\title{
Relationships in pain: The experience of relationships to people living with chronic pain in rural areas
}

Joanne Tollefson RN BN MPHTM PhD

Senior Lecturer (Retired), School of Nursing, Midwifery and Nutrition, James Cook University, Cairns, Queensland, Australia

Kim Usher RN DipHSc BA MNSt PHD

Professor and Associate Dean for Graduate Research Studies, School of Nursing, Midwifery and Nutrition, James Cook University, Cairns, Queensland, Australia

Kim Foster RN PhD

Associate Professor Mental Health Nursing, Sydney Nursing School, University of Sydney, Camperdown, New South Wales, Australia Accepted for publication May 2011

Tollefson J, Usher K, Foster K. International Journal of Nursing Practice 2011; 17: 478-485

Relationships in pain: The experience of relationships to people living with chronic pain in rural areas

The aim of the study was to develop new understanding of the lived experience of relationships for rural people living with chronic pain. Rural residents have greater difficulty accessing health services and providers. This is especially important to those living with chronic pain who often find themselves isolated from professionals who could potentially offer support. A phenomenological study with seven participants who had experienced chronic non-malignant pain for 2-29 years (Mean $=13$ ) was recruited via a number of approaches and data analyzed using van Manen's framework. The themes that emerged from the analysis were as follows: pain as silence; privacy as a way of protection; no place out here to get support; and dealing with health-care professionals who do not understand. Lack of specialist services and support in rural areas means people with chronic pain are placed in even more vulnerable situations. Nurses remain at the forefront of service delivery in rural areas; hence, their role in management of people with chronic pain is vital in supporting them to maintain meaningful contact with others, including health professionals.

Key words: chronic pain, nursing, qualitative research, rural.

Correspondence: Kim Usher, School of Nursing, Midwifery and Nutrition, James Cook University, PO Box 6811, Cairns, Qld 4870, Australia.Email: kim.usher@jcu.edu.au; Kim Foster, Sydney Nursing School, University of Sydney, 88 Mallett St., Camperdown, NSW 2050, Australia.Email: kim.foster@sydney.edu.au

\section{INTRODUCTION}

Chronic pain is pain that lasts continuously or intermittently for a period of 6 months and its cause is often unknown. ${ }^{1}$ A complex phenomenon, health-care professionals are often required to deal with chronic pain on a daily basis. People who reside in rural areas can have 
greater difficulty accessing health services and health providers. This is especially important to those living with chronic pain who find themselves isolated from the services and the professionals who could potentially offer them support. Relationships with partners, family members, the community and health providers are paramount to these people who can struggle to manage their activities of daily living. Yet the personal experience of chronic pain has received relatively little attention to date, and the impact of chronic pain on people who reside in rural areas is largely absent in the literature.

In Australia, rural and remote communities are extremely diverse and constitute heterogeneity of demographic and economic bases. The population's age, gender, ethnic/cultural background, occupation, socioeconomic status and communities' social/economic structures, health and education facilities and size vary greatly. To discuss such a diverse population, a definition of the term 'rural' is required. However, the term has many definitions and can be difficult to define. For the purpose of this study, the Accessibility/Remoteness Index for Australia (ARIA) was used to determine rurality. ${ }^{2}$ The ARIA scale was developed as a measure of remoteness and the scale ranges from 0 to 15 ; the higher the score, the more remote from services. Participants included in the study had an ARIA score of five or greater. This meant that most of the participants lived a minimum of $500 \mathrm{~km}$ from the nearest specialist services, had restricted access to goods and services and had reduced opportunities for social interaction. ${ }^{3}$

This study was undertaken as the impact of chronic pain on interpersonal relationships is still relatively unknown, especially in relation to people in rural areas. The goal was to provide a means for the development of strategies that might be used in the future to better support people with chronic pain who reside in a rural location.

\section{BACKGROUND}

Australians living in rural and remote areas experience different health status than their urban compatriots with both morbidity and mortality being higher. ${ }^{3-7}$ Compared with cities, the life expectancy of people in regional areas is 1-2 years lower and up to 7 years lower in remote areas. Furthermore, people living in regional and remote areas are more likely to report asthma, arthritis and bronchitis. ${ }^{3}$ This difference in health status is attributed to geographical distance from services and a relative lack of health-care personnel and resources. ${ }^{8}$ People living with chronic pain in rural areas are often denied access to necessary health and support services, which makes living with their condition more difficult. Estimates of the numbers of people living with chronic pain in developed countries vary according to the definitions of chronic pain used and the methods used to obtain the statistics, although the incidence of chronic pain is fairly stable in developed nations at between 15 and 25\% of the community. ${ }^{9}$ Underreporting of chronic pain states is suspected because some studies indicate that the magnitude of the problem is greater than reported. ${ }^{10}$ Not only are monetary and societal costs attributable to chronic pain, but the personal costs are also high. People lose self-esteem, their body image changes, there is an alteration in personal relationships and family roles, and there is a loss of trust in the health-care system. ${ }^{11}$

The family forms the immediate context for the person living with chronic pain, and familial interactions can assist or hinder the person in adjusting to the pain experience. Smith and Friedemann found that the impact of chronic pain on family relationships led to emotional distress, distancing from family members, inability to share difficult feelings, intense mutual involvement with family and identification with others' problems, and family isolation from the community. ${ }^{12}$ Family dynamics are thus altered by the experience of chronic pain. Given the relative isolation of rural dwellers from health services where support would normally be found for people living with chronic pain and because little is currently known about the relationships of rural dwellers experiencing chronic pain, the current study was conceived.

\section{METHOD}

A qualitative, phenomenological study was chosen as the most suitable method to explore the experience of relationships for people living with chronic pain in rural areas. Hermeneutical phenomenology is designed to unveil otherwise concealed meanings and hence to make the connection between what is familiar and unfamiliar in our worlds. It is therefore useful for studying topics central to humans' life experience such as the importance of relationships for people living with chronic pain in rural communities. ${ }^{13}$

\section{PARTICIPANTS}

A purposive sample was used to achieve the most relevant participants who could explain the phenomenon of interest. ${ }^{14}$ Participants for this study were recruited because 
they (i) were homogeneous in the fact that they all lived in a rural area with an ARIA score of three or greater and could therefore be expected to illuminate that aspect of their relationships and the pain experience and (ii) had an intensity of the experience of interest (chronic pain) and could therefore be expected to help with the exploration of what it is like to be in a relationship for people in chronic pain and living in rural areas. Participants were recruited via a number of methods such as local media announcements, word of mouth, introductory letters sent by general practitioners (GPs) and registered nurse (RN) referrals from a pain clinic at the nearest regional town. Seven participants were interviewed and their ages ranged between 23 and 55, which included three males and four females. The causes of participants' pain included fibromyalgia, low back pain, arthritis, whiplash injury and trauma from an accident.

\section{INCLUSION CRITERIA}

To be included in the study, the participants had to meet the following criteria:

- Aged over 18 years;

- Have experienced chronic non-malignant pain diagnosed by a doctor for more than 2 years;

- Fluent in English;

- Capable of giving informed consent; and

- Reside in a rural town with an ARIA rating greater than three.

\section{ETHICAL CONSIDERATIONS}

Ethical approval was sought and received from the relevant University Human Research Ethics Committee. Participants were provided with information sheets and were asked to sign consent forms prior to interview. They were also provided with a telephone number of a counselling service to contact if they were distressed in any way as a result of the interview. This service was not required by any participants to our knowledge. Pseudonyms were allocated to all participants after the initial interview and were used in all resulting publications to help protect the identity of the participant.

\section{INTERVIEWS}

A conversational-type interview of $\sim 1 \mathrm{~h}$ was organized with each participant at a convenient place and within a mutually agreeable time frame. In particular, we used open-ended conversational-type interviews where the participants were encouraged to tell their own story with little prompting from the researcher. This type of informal interview is likely to reap more from participants than a more structured approach. ${ }^{13}$ Initially, demographic characteristics were sought, including age, residence, disease process, pain levels and the length of time the pain had been endured. This was used as an 'ice-breaker' to dispel tension and gain the participant's confidence. Participants were then asked questions such as: Can you tell me how living with chronic pain has impacted on your relationships within your family and with others? The conversations were audiotaped with the participant's consent.

\section{ANALYSIS}

Data from the study were analyzed using van Manen's thematic approach. ${ }^{15}$ Each verbatim transcription was read through although listening to the tape to resituate the researcher into the conversation. The interpretation process was begun by rereading the transcription and identifying contradictions between the tone, hesitations and silences in the material and the words used. Following this, each line of text was read for meaning, then larger, meaningful groupings of words were read for central ideas and meaning. Writing and rewriting then followed an integral part of van Manen's and other phenomenological analytic approaches. ${ }^{15}$

\section{FINDINGS}

The existential essence of relationality illuminated the experiences of the participants within their relationships - initially with their significant others, then with their intimate and close circle of friends and with the wider circle of friends and neighbours. The essence also includes the individual's relationships with health-care professionals. Four themes emerged: pain as silence, privacy as a way of protection; no place out here to get support; and dealing with health-care professionals who do not understand.

\section{Pain as silence}

Although pain was a major aspect of their life, most participants described minimizing the extent of their pain, even when talking to close family members, in order to avoid upsetting or burdening their significant others. As Diane said: I don't tell her (15-year-old daughter) about the pain. I don't want her to worry and I don't want her to then decide that she won't do things because she thinks she should be home looking after me, you know. 
There are several reasons for this silence, and each bears a relationship to the others. Stoicism, privacy, autonomy and dignity were intimately bound together to protect the individual from the outside world. Brigid said: I don't want anyone feeling sorry for me and I don't want anyone thinking, you know, I'm worse off -It's something I live with and I don't ask other people to live with it, especially friends.

Self-reliance and stoicism is typical of rural people, ${ }^{16}$ so it is not surprising that it was evident in participants' narratives. Stoicism arises from previous experience, cultural mores and religious traditions. The quiet endurance of adversity and setbacks with courage and grace is a rural cultural expectation. ${ }^{17}$ Diane feels that she has to apologize for her inability to contribute to the various committees and functions she attends because, as a relatively young woman of 45 , there is an automatic presumption that you are more able to contribute than older, frailer-looking members and workers.

Reticence implies a reluctance to speak of the pain. This is one of the recurring themes from participants, and it seemed that the worse the pain was, the more reticent the individual. For instance, Carl told all of his family of origin that he has this painful condition (by sending them the brochures the doctor gave him) but downplayed the magnitude of the pain on a daily basis, answering the inevitable 'How are you today?' with $\mathrm{Oh}$, well enough and not mentioning the pain specifically. Diane said, You hurt all the time and you worry it's going to hurt worse . . But what can you do? People don't want to hear it, they don't want to know that you're more miserable than they are, I think a lot of the time- you know. It was as if there is a tacit agreement that pain as a topic of conversation was to be avoided.

Diane has a further perspective on her reluctance to speak of the pain as she attempts to maintain independence: I sort of have the feeling that I want to wait 'til things get really bad before I impose on their time any more, you know, like there's a sense of not wanting to empty the favour bucket. Asking for assistance is problematic for most people because in Australian culture and especially in rural Australia, rugged, independent individualism is an expected and valued trait. ${ }^{18}$ Whereas pain might be silenced in any person with chronic pain, in rural areas it seems that the silence on pain might be a way of life that is part of being a country person. The need to silence the pain therefore results in guilt within relationships, including with intimate partner and other town folk. There also seems to be an inability to continue to participate in family, work and social life, and understanding the effect that this has on family and friends leads to a sense of guilt. There is guilt at being unable to assume normal (or previously held) role responsibilities and especially intimate roles-We don't have a sex relationship in the marriage because [of the] pain (Gary). Social obligations and outings could only be spontaneous because of the unpredictability of the intensity or the constant presence of the pain.

\section{Privacy as a way of protection}

Arendt names pain as one of the intimate parts of our lives and it is thus assigned to our private selves. ${ }^{19}$ Privacy is considered very precious as it can keep outsiders from seeing what goes on in our undisclosed lives and from browsing in our souls. The intimate and thus private sphere of our lives is developed through the processes of learning and adhering to social rules to avoid some sort of punishment. ${ }^{19}$ Social rules are pervasive and Diane suggested that . . A Australians I think have a real reticence about asking personal questions in general. Gary, too, found that friends were unwilling to approach him, and says that after he got sick, I avoided them (friends) but there was avoidance from them too, because they - I was just quiet, hunched over, obviously in pain.

Choosing to discuss information, feelings and judgments with those we select is a function of privacy. Diane says that there were a few friends to whom she was willing to disclose the level of pain she was enduring: Yeah, some people I would (tell) a lot more to than others. You know some friends... I've known for a long time now, I'll just come right out and say Look, everything's hurting today, I'm having a horizontal day. I'm just going to stay in bed in the electric blanket. Sorry.

\section{No place out here to get support}

Participants also found that family roles changed when living with chronic pain, and often their role responsibilities (e.g. financial responsibilities, child rearing, and house and yard work) were shifted onto the closest other, with that person assuming the altered responsibilities as well as their own. For example June says her husband comes home late of a night and then turns around and cooks his tea and has had to do the shopping when she has a bad day. Social isolation often resulted when outings were cancelled because of the pain, and the closest other was reluctant to leave the person living with pain alone, with the increased levels of pain.

Brigid says, I have no family support but she does have a significant friend who is her next of kin - no relation - she's 
my next of kin, she's on my medic alert card, she's on my organ donor card, my will, my burial and my bank, who had become Brigid's de facto family. This friend provided comfort and support for years. Diane has a daughter and her parents live close. Her parents help out with driving and going to collect my medication for me (a roundtrip of $5 \mathrm{~h}$ ). Diane says I'm fortunate that my parents live nearby so they're available to sort of pick up the slack.

Pets were part of the family support system as well. Brigid, Gary, Leah and June all had dogs as companions. June had a young dog that was much cherished and she said, they give you that much bloody support and comfort, they do. Brigid has a beloved pet, Tippy, who was integral to her 'family', providing companionship and comfort. Tippy lived with Brigid and accompanied her to town on the scooter . . . on Sunday, I take my time - we call in and see a few friends. Moreover, Gary says he went and got a little dog and she's just about the best mate at the time . . so that's kept me-oh no, it gave me something to be responsible for, I suppose as it's a living animal.

However, sometimes support from others was not there. Diane said, sometimes when I'm just having a bad patch . . . people become then sort of become almost aggressive, especially when I have to say Look, I'm sorry, no, I can't come to this or be part of that or do the other things. More often, in a small town or country area, there was good support — neighbours rallied around. Again, Diane demonstrates this. A couple of months ago I got sick and had some trouble breathing and they rushed me off to hospital in an ambulance and my next-door neighbour collected my daughter from school, and then the next day she had a stroke and she was carted off to a different hospital in an ambulance, so one of my neighbours looked after my daughter because my parents were in New Zealand on holidays as these things always happen, so one of their neighbours then was contacted by one of my neighbours to say that I was in hospital so then my parents had organised for them to feed their animals and look after their house and they came round and sorted out my house and brought casseroles for my daughter and came up and did my washing and all of those sorts of things, and all of this sort of happened sort of via the community grapevine really. And I mean you would never get that in a city environment.

Support from health professionals though was often not available in small rural towns as those that were there were usually overworked and others just came for 'locum' periods or holiday relief. Brigid says, There's no place out here where you can go and sit and have a good yarn about it (the pain experience) except to my GP, and he's back today. Yet even when they were available, the relationship between the patient with chronic pain and the health professional could be strained.

\section{Dealing with health-care professionals who do not understand}

Sharing confidences with another person generally increases intimacy and paradoxically produces a tension, as we are giving another person access to our innermost thoughts, which might alter the intimate relationship negatively. Health-care professionals hold a privileged position in our society in that they are trusted with private information without reciprocating. Disclosing personal information in a small town can be threatening to personal integrity because there is often a very active and efficient 'grapevine', permitting everyone in town to soon know an individual's business if the person confided in is not discreet. Brigid says the reason she could talk to a psychologist was because she wasn't living in this town and she was helping me through a very bad time and of course being a professional someone that - you know small towns? How word of mouth gets around so quick. So I know it wasn't going any further than her.

Participants highlighted that trust can be eroded when the health professional does not acknowledge the individual's involvement in their care plan. Brigid reveals this deterioration in the relationship she had with the previous GP in her town: Well, the one before Dr P. didn't understand, just didn't know anything about this and wasn't interested. He just said straight out that wasn't his line - he wasn't going that way. And he couldn't understand, I suppose, the amount of pain. He was forever telling me that 'don't do this, don't do that'. In his opinion I should have been just be sitting in my chair you know, knitting the rest of my life away. This is especially problematic in small rural towns as there is often only one GP available. Many small town hospitals and clinics are also serviced by locum doctors, or 'fly-in-fly-out' arrangements, and agency nurses often staff the hospital and surgery. Brigid says, They do a good job, but they are mostly agency nurses - come for six weeks. We've only got - at present we've only got two local people-two sisters.

Another facet of living in a small town was the necessity to rely on an often overworked health-care professional. Carl says, There is a doctor in town but - and he was a very good doctor I started going to - but he, to me, was overworked and I used to talk to him about a few things and he would do his best. As a result, Carl now travels a couple of hours to my Doctor on the coast who was the initial Doctor that stuck with 
me. People in small towns often must travel long distances to see the GP of their choice.

\section{DISCUSSION}

Participants in this study described being silent about pain with their significant others in order to protect themselves and their loved ones from the fallout of the pain experience. Dickson and Kim also found this reticence in their cohort of Korean-American women living with chronic osteoarthritic pain. ${ }^{20}$ Blomqvist and Edberg interviewed elderly folk who lived with chronic pain and found that pain threatened these people's self-image as independent individuals. ${ }^{21} \mathrm{~A}$ large percentage of these people tried to hide the pain with silence and a reluctance to complain. They were unwilling to put the strain of their pain onto their significant others. These qualitative studies support the findings of the current study. Dewar and Lee found that although the significant other was a valuable source of support, bearing the condition was essentially up to the individual, and this realization was instrumental in adjusting to their circumstances. ${ }^{22}$ Participants in the current study also indicated that hiding the condition and the extent to which it impacted on their life was an effective strategy that assisted them to live with the pain. Living in a small rural town appears to have been of particular benefit for some of the participants, as it provided them with the opportunity to remove themselves from family and other obligations and avoid contact with others when desired, enabling them to hide their pain from others.

Relationships with others revealed by the participants varied from firmly supportive through to apathetic or even destructive. However, whether positive or negative, each interaction described was the result of the person living with chronic pain inserting themselves into the human world and enlisting the help of other to accomplish something. ${ }^{19}$ The rural community involvement and concern was particularly important and not found in other previous studies of people living with chronic pain. Friends and neighbours helping when the person living with chronic pain could not accomplish their chores or offering a cheery word on the street were integral to participants' experiences of small town living.

Pets are part of many families and provide companionship, unconditional love and a snuggle factor of touch and warmth. The majority of the participants in the current study found pets provided both support and comfort to them. Strandmark substantiates the importance of pets to some of her participants, ${ }^{23}$ as does the review by Halm. ${ }^{24}$
Johnson et al., although not a qualitative study, reported an increased perception of well-being and improved health by those who had had a series of pet therapy visits. ${ }^{25}$ Other studies reported positive results of research into pet therapy, but no other qualitative studies on pets or companion animals with people with chronic pain were located.

The issue of relating to health-care professionals was a significant problem raised by participants. They spoke about the difficulty in establishing an effective interaction with their health-care professional. Many personal, professional and situational factors contributed to the difficulties. Often the GP was from a different culture and spoke English as a second language. Discussions of the pain problem were difficult, with accents sometimes getting in the way when the GP was from another culture or country; not surprising given that international medical graduates are becoming the mainstay of the medical workforce in regional and remote areas of Australia. ${ }^{26}$ Furthermore, GPs who work in small country towns are often very busy people, and devoting a lot of time to listen to someone who is living with chronic pain takes time from other patients who need attention (whose ills might be easier to deal with and might result in a cure). As living with chronic pain is known to limit a person's social interactions and willingness to explore opportunities and treatment options, ${ }^{27}$ this might help explain the participants' feelings that GPs were unhelpful. Although participants were particularly asked about any contact they had with nurses in their professional capacity, all denied having any meaningful interactions with nurses. This is unfortunate, as nurses have much to offer people living with chronic pain, especially as they are often the only health-care professional available to rural residents. The rural nurse should be complementing and supporting the work of the GP by undertaking these roles. ${ }^{28}$ In fact, nurses who specialize in working in rural areas might be better placed than doctors to manage people with chronic pain in the future.

\section{LIMITATIONS}

This study was limited by a number of factors. The study participants were drawn from rural towns within a small geographic location. It is possible that others with chronic pain residing in other rural areas might have different stories to tell. Furthermore, the study attracted participants by various methods, and seven participants were included in the final sample. It is possible that we missed identifying or including rural people who might have 
experienced their life with chronic pain differently. Sample size in phenomenological studies usually ranges from six to 12 as the goal is depth of understanding of the phenomenon. ${ }^{29}$ Furthermore, it is also usual practice to cease data collection when redundancy is achieved, which infers that no new thematic material is being heard in interviews. ${ }^{16}$

\section{CONCLUSION}

Relationships are crucial to the well-being of people who live with chronic pain. Health-care professionals must understand the reticence of rural people with pain to reveal the true extent of their condition and use their assessment skills appropriately to improve the care and outcomes for this challenged group. The lack of specialist services and support in rural areas means people with chronic illnesses and conditions such as chronic pain are placed in vulnerable situations. Given the chronic health workforce shortages experienced in rural areas, the delivery of adequate health services to rural people is jeopardized. Nurses remain at the forefront of service delivery in rural settings; hence, their role in regard to the management of people with chronic pain is very important. However, nurses were conspicuous by their absence from the conversations in this study. Although nurses are the largest group of health-care professionals, the people in this study reported few helpful contacts with nursing staff. Many of the strategies for adequately managing and adapting to pain are educational-self-management, pacing, knowledge of the condition and effective use of analgesia - and nurses should have a significant role in this education. ${ }^{30}$ Efforts to recruit more rural-based RNs to undertake further studies, especially in pain management, could offer people in rural Australia another avenue of assistance in living with chronic pain.

\section{REFERENCES}

1 International Association for the Study of Pain (IASP). Classification of Pain. Seattle, WA, USA: IASP Press, 1986.

2 Bamford E, Dunne L. Quantifying access to health facilities. Paper presented at the 5 th National Rural Health Conference, 2001.

3 Australian Institute of Health and Welfare (AIHW). Rural, regional and remote health: indicators of health status and determinants of health. Rural Health Series No. 9, Cat. No. PHE 97. Canberra: AIHW, 2008. Available from URL: http:// www.aihw.gov.au/WorkArea/DownloadAsset.aspx?id= 6442459831. Accessed 24 March 2011.
4 Preston G. Mapping the differences: an examination of hospitalization of remote, rural and metropolitan Australians. Paper presented at the 5th National Rural Health Conference, 2001.

5 Hays R. Practicing Rural Medicine in Australia. Melbourne, Victoria, Australia: Eruditions Publishing, 2002.

6 Smith JD. Australia's Rural and Remote Health - A Social Justice Perspective. Croydon, Victoria, Australia: Tertiary Press, 2004.

7 Strasser R. Rural health research: have we turned the corner? The Australian Journal of Rural Health 2000; 8: 249 253.

8 Eyles R, Smith B. Rural health in Queensland: a changing focus. The Australian Journal of Rural Health 1995; 3: 186191.

9 Brennan F, Carr DB, Cousins MJ. Pain management: a fundamental human right. Pain Medicine 2007; 105: 205221.

10 Mayer D, Torma L, Byock I, Norris K. Speaking the language of pain. The American Journal of Nursing 2001; 101: 44-50.

11 Sturgeon A, Zautra A. Resilience: a new paradigm for adaptation to chronic pain. Current Pain and Headache Reports 2010; 14: 105-112.

12 Smith AA, Friedemann ML. Perceived family dynamics of persons with chronic pain. Journal of Advanced Nursing 1999; 30: 543-551.

13 Streubert Speziale HJ, Carpenter DR. Qualitative Research in Nursing. Advancing the Humanistic Imperative, 3rd edn. New York: Lippincott, Williams and Wilkins, 2003.

14 Llewellyn G, Sullivan G, Minichello V. Sampling in qualitative research. In: Minichello V, Sullivan G, Greenwood K, Axford R (eds). Handbook of Research Methods for Nursing and Health Science. Frenchs Forest, NSW, Australia: Pearson Educational Australia, 2004; 295-318. Chapter 9.

15 van Manen M. Researching Lived Experience: Human Science for an Action Sensitive Pedagogy. London, Canada: The Althouse Press, 1990.

16 George SR, Thomas SP. Lived experience of diabetes among older, rural people. Journal of Advanced Nursing 2010; 66: 1092-1100.

17 Heenan D. The factors influencing access to health and social care in the farming communities of County Down, Northern Ireland. Ageing and Society 2002; 26: 373-382.

18 Bigbee J, Lind B. Methodological challenges in rural and frontier nursing research. Applied Nursing Research 2007; 20: 104-106.

19 Arendt H. The Human Condition. Chicago, IL, USA: University of Chicago Press, 1998; 114.

20 Dickson GL, Kim JI. Reconstructing a meaning of pain: older Korean American women's experiences with the pain of osteoarthritis. Qualitative Health Research 2003; 13: 675688. 
21 Blomqvist K, Edberg AK. Living with persistent pain: experiences of older people receiving home care. Journal of Advanced Nursing 2002; 40: 297-306.

22 Dewar A, Lee EA. Bearing illness and injury. Western Journal of Nursing Research 2000; 22: 912-926.

23 Strandmark M. Ill health is powerlessness: a phenomenological study about worthlessness, limitations and suffering. Scandinavian Journal of Caring Sciences 2004; 18: 135-144.

24 Halm MA. The healing power of the human-animal connection. American Journal of Critical Care 2008; 17: 373-377.

25 Johnson RA, Meadows RL, Haubner JS, Sevedge K. Animal-assisted activity among patients with cancer: effects on mood, fatigue, self-perceived health, and sense of coherence. Oncology Nursing Forum 2008; 35: 225-232.

26 Department of Health and Ageing (DOHA). General Practitioner Statistics. Canberra: DOHA. 2010. Available from URL: http://www.health.gov.au/internet/main/ publishing.nsf/Content/General+Practice+Statistics-1

Accessed 24 March 2011.

27 Van Doesum K, Hosman C, Riksen-Walraven J. A modelbased intervention for depressed mothers and their infants. Infant Mental Health Journal 2005; 26: 157-176.

28 Daly J, Bryant R. Professional organizations and regulatory bodies: forging and advancing the role of nurses in Australian primary care. Contemporary Nurse 2007;26: 27-29.

29 Morse J. Designing funded qualitative research. In: Denzin NK, Lincoln YS (eds). Handbook of Qualitative Research. Thousand Oaks, CA, USA: Sage, 1994; 220-235.

30 Tollefson J, Piggot K, FitzGerald M. Management of chronic pain. In: Chang E, Johnson A (eds). Chronic Illness and Disability. Sydney, Australia: Elsevier, 2008; 110-125. 